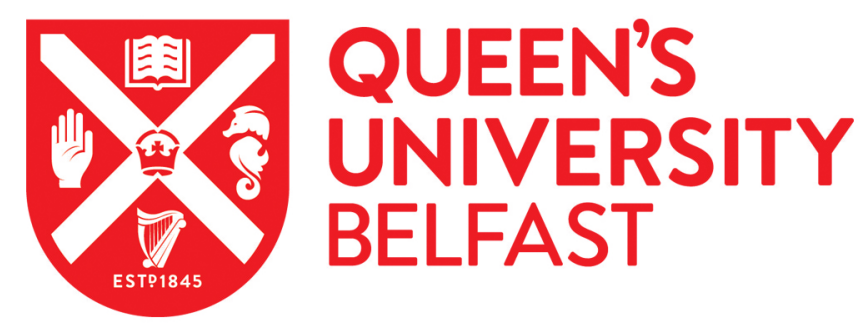

\title{
Characteristics of Reported Pediatric Medication Errors in Northern Ireland and Use in Quality Improvement
}

Conn, R. L., Tully, M. P., Shields, M. D., Carrington, A., \& Dornan, T. (2020). Characteristics of Reported Pediatric Medication Errors in Northern Ireland and Use in Quality Improvement. Paediatric drugs. https://doi.org/10.1007/s40272-020-00407-1

Published in:

Paediatric drugs

Document Version:

Peer reviewed version

Queen's University Belfast - Research Portal:

Link to publication record in Queen's University Belfast Research Portal

Publisher rights

Copyright 2020 Springer. This work is made available online in accordance with the publisher's policies. Please refer to any applicable terms of use of the publisher.

\section{General rights}

Copyright for the publications made accessible via the Queen's University Belfast Research Portal is retained by the author(s) and / or other copyright owners and it is a condition of accessing these publications that users recognise and abide by the legal requirements associated with these rights.

Take down policy

The Research Portal is Queen's institutional repository that provides access to Queen's research output. Every effort has been made to ensure that content in the Research Portal does not infringe any person's rights, or applicable UK laws. If you discover content in the Research Portal that you believe breaches copyright or violates any law, please contact openaccess@qub.ac.uk. 


\section{Characteristics of reported pediatric medication errors in Northern Ireland and use in quality improvement}

Richard L Conn ${ }^{1 \star}$, Mary P Tully², Michael D Shields ${ }^{3}$, Angela Carrington ${ }^{4}$, Tim Dornan ${ }^{1}$

1. Centre for Medical Education, Queen's University Belfast, Belfast, United Kingdom, BT9 7BL

2. Division of Pharmacy and Optometry, School of Health Sciences, University of Manchester, Manchester Academic Health Sciences Centre (MAHSC), Manchester, United Kingdom

3. Centre for Experimental Medicine, Queen's University Belfast, Belfast, United Kingdom, BT9 7BL

4. Medicines Governance Team, Belfast Health and Social Care Trust, Belfast, United Kingdom

* Corresponding author

E-mail: r.conn@qub.ac.uk

ORCID iD: https://orcid.org/0000-0002-2564-254X

Running heading: Reported medication errors in children 


\title{
Abstract \\ Background
}

To protect children from harm, clinicians, educators, and patient safety champions need information to direct improvement efforts. Critical incident data, often disregarded as a source of evidence because under-reporting makes them an inaccurate measure of error rates, could provide this.

\begin{abstract}
Aim
Our aim was to identify key targets for pediatric healthcare quality improvement. The objective was to evaluate the types, characteristics, and areas of risk within reported medication errors in pediatric patients.
\end{abstract}

\section{Methods}

Retrospective study of a large regional dataset of 1522 pediatric medication errors reported from secondary care between 2011 and 2015, including all hospitals and community pediatric settings in Northern Ireland. Characteristics included: error severity; patient age; drug involved; error type; and area of practice. Two academic pediatricians, a senior medicines governance pharmacist, a Reader in Pharmacy Practice, and a Professor of Medical Education analysed the data. Validity checks included comparing the findings against key published literature and discussion by a practitioner panel representing five multidisciplinary stakeholder groups.

\section{Results}

Neonates, particularly in intensive care, were implicated in $19 \%$ of all errors. The medications most represented in risk were antimicrobials, paracetamol, vaccines, and intravenous fluids. The error types most implicated were dosing errors (32\%) and omissions (21\%).

\section{Conclusions}

Incident reports identified neonates, a shortlist of drugs, and specific error types, associated with modifiable behaviours, as priority improvement targets. These findings direct further study and inform intervention development, such as specific training in 
calculations to prevent dosing errors. Involving experienced practitioners both endorsed the findings and engaged the practice community into their future implementation. The utility of incident reports to direct improvement efforts may offset limitations in their representativeness.

\section{Key points}

- Critical incident reports can support medication safety by providing information on characteristics and nature of errors

- Discussion with stakeholders and review of selected literature can offset incidents' lack of representativeness and support their validity

- In pediatric medication safety, factors associated with risk of error included neonatal care, dosing and timely administration, and use of common drugs such as antimicrobials, paracetamol, IV fluids and vaccines 


\section{Introduction}

In their third Global Patient Safety Challenge, Medication Without Harm, the World Health Organisation urged quality improvement initiatives to target 'high-risk situations'.[1] Using medication in children, in whom errors are more common and more likely to cause harm than in adults[2,3] - is a case in point. Improvements are 'long overdue',[1] but have been hampered by a lack of pertinent information about key characteristics of errors.[4] Most studies of pediatric medication safety provide evidence about the overall prevalence of errors and the efficacy of specific interventions[3,5-7] rather than the specific drugs and error types that cause harm. More specific information of this nature could break down this complex problem and direct improvement effort towards high-risk areas that offer greatest potential for benefit.

Adult studies provide this type of information, but extrapolation is of limited use because medication use in children differs. For example, many drugs used routinely in adult practice are rarely given to children and pediatric practice more often needs individualised dosing and off-license medication use.[8] Moreover, children frequently receive liquid medicines; often these require extemporaneous preparation as 'specials', whose lack of standardisation may complicate use. Error patterns also differ; for example, dosing errors, particularly potentially-lethal tenfold errors, are more common in children.[3,9] An alternative to learning from adult errors is to make better use of routinely reported critical incidents. This source of information, often maligned, has important strengths. Incident reports are directly related to real clinical practice, contemporaneously reported, and readily available. They show who was affected, where errors occurred, and what drugs were involved. Staff members choose to report errors and provide rich narrative information precisely because this will help prevent future harm.

Despite these strengths, incident reports' potential to improve pediatric medication safety has not been fully realised. In risk management their use is usually at local level and focuses on detailed analysis of small numbers of incidents. In published research, most work has been conducted in specific settings (e.g. neonatal intensive care units (NICU)[10,11]), with specific medication groups (e.g. sedation[12]), or on specific error 
types (e.g. tenfold dosing errors[13]). The few studies carried out in general pediatric settings have typically been on a small scale[14] compared to research in adults [15], and have estimated the prevalence of errors and their response to interventions. Critics have pointed out the shortcomings of this approach, arguing that using incident reports for epidemiological purposes or as a measure of changes is inappropriate.[16] In support of this, they show that error rates derived from incident data are lower than rates derived from drug chart review or direct observation, $[5,17,18]$. These critiques rightly contend that under-reporting, incomplete data, and potential bias error compromise incident reports' representativeness.[19,20] The unintended consequence of criticising the reliability of incident analysis is that this has obscured the potential utility of reported incidents to improve medication safety. Specifically, identifying risks rather than measuring rates[16] would make incident reports useful, particularly if information from reports was triangulated against other sources of information to increase confidence in findings.

Following a lead from the UK Royal College of Physicians,[21] we reasoned that incident data could make an important contribution to setting quality improvement priorities and set out to conduct a retrospective observational analysis of a large, regional dataset of reported pediatric medication errors. Our aim was to identify priority targets for quality improvement by analysing error types, characteristics and areas of risk, and triangulating our findings against published evidence and the informed opinion of an advisory panel of experienced clinicians.

\section{Methods}

To identify key targets for pediatric healthcare quality improvement, our objective was to evaluate the types, characteristics, and areas of risk within reported medication errors in pediatric patients.

\subsection{Study design}

Analysis of a large set of errors reported from a geographically defined region, part of the UK National Health Service, whose error reporting is coordinated between all healthcare providers, making regional analysis of incident reports possible. 


\subsection{Setting}

In collaboration with a regional medication safety group, the Northern Ireland (NI) Medicines Governance Team, we obtained all reported medication incidents occurring in pediatric patients aged 0-16 years, between 2011 (when electronic reporting was first established in NI) and 2015, in all five NI Health and Social Care (HSC) Trusts. These organisations administer health and social care across $\mathrm{NI}$, to a population of 1.8 million, including 380,000 children aged 0-16. Children receive care in various settings. There is a large regional children's hospital, with dedicated pediatric emergency department and regional neonatal unit. There are seven district general hospitals with children's wards, maternity services and neonatal units, as well as several others with pediatric outpatient clinics, ambulatory pediatric care, midwifery-led units, general emergency departments and other services which treat patients of all ages (e.g. ophthalmology, orthopedics). Children are also looked after in community settings such as community pediatric centres, school health services, and respite and care facilities. Hospitalised young people usually receive care on adult wards from age 14 or 15 years.

Staff employed by HSC Trusts voluntarily report critical incidents for local risk management purposes, primarily via an electronic database on hospital computers. Staff are encouraged to report all adverse events where harm, or the potential for harm, occurs. Incidents are held within individual HSC Trusts. Reports contain categorical information (incident type, harm, location etc.), and a free-text description of what happened and what action was taken in response. Forms contain guidance on describing incidents, but staff decide on the level of detail to include.

All medication incident reports are reviewed by medicines governance pharmacists (MGPs) who are trained to process, extract and analyse incidents. Consistent procedures are used across all HSC Trusts. They routinely check stage of medication delivery (prescribing/administration/dispensing/monitoring/other), error type (wrong dose/wrong medicine etc.), drug involved, and level of actual and potential harm for all incidents. When necessary they seek further information from staff or check patient records.

Incident type labels applied by MGPs are similar to the WHO Conceptual Framework for the International Classification of Patient Safety.[22] We used its terminology where 
possible but, as this was analysis of routinely-collected data, it was not possible to change existing category labels.

\subsection{Data extraction}

MGPs within each Trust extracted all medication incidents relating to pediatric patients aged 0-16 years in all NI hospitals and community settings, from July 2011-July 2015. This was intended to include all children who were patients, not just those cared for in dedicated pediatric settings. To include reports that might have been missed because patient age was not recorded, MGPs also carried out a second extraction of medication incidents coded as occurring in specific pediatric settings. The final dataset included community settings but excluded primary care.

For the purpose of this study, MGPs used a protocol provided by us to extract incident data into a Microsoft Excel spreadsheet. They removed identifiable details, applied pseudonyms to Trust and site names, and double-checked that incidents were appropriately categorised. A Medicines Governance Team administrator combined these proformas into a single, regional dataset.

\subsection{Data processing}

$R L C$ reviewed all 1552 extracted incidents. Accuracy of classification was checked and drug categories (for example, antimicrobials, anticonvulsants) were applied. Intravenous (IV) fluid errors were included within medication incidents. The focus of this research was medication error at the individual patient level. We therefore excluded incidents not relating to individual patients (e.g. a medication cabinet being left unlocked), adverse drug reactions where no error had taken place, errors occurring in primary care but reported in secondary care, and errors relating to medical devices or equipment. Where incident reports referred to multiple errors at more than one stage of medication delivery (typically, errors in both prescribing and administration), these incidents were duplicated and classified at both applicable stages.

\subsection{Analysis and identification of risk}

We defined risk as probability of occurrence of error combined with the potential severity of resultant harm. $[23,24]$ We deemed that 'high-risk' aspects of practice - in 
terms of error types, patient groups, clinical areas or medications - could represent quality improvement targets.

We used descriptive statistics to summarise characteristics of reported medication errors (type, sub-type, harm, age of patient, area of practice, reporter group, drug involved) in order of frequency. Because incident severity contributes to risk, we planned to analyse incidents which led to severe harm or death separately, but none were reported within the study period. We chose to focus on errors in prescribing and administration because they were commonest, and we judged that they would make relevant targets for $\mathrm{Q}$ in frontline clinical settings.

By reflecting on and discussing the reported error characteristics, RLC and AC agreed on preliminary areas of risk. In a process of triangulation,[25] we then assessed these findings against two other sources of evidence. First, RLC discussed the results of the analysis (Tables 1-4) with five stakeholder advisory groups, asking them to reflect on the commonly-occurring incident types and, based on their experience, advise on their validity and importance. These groups were: pediatric teams in two hospitals; a hospital drug and therapeutics committee; a regional quality improvement (QI) body; and the medication safety sub-group of the statutory body responsible for health and social care in NI. Second, we reviewed other key sources of peer-reviewed evidence and grey literature - including prospective observational studies, other critical incident studies, and patient safety alerts - to establish prior knowledge about the prevalence and severity of provisionally identified areas of risk. Combining information from incident data and the two validation steps, the entire multidisciplinary research team made up of two academic pediatricians, a senior medicines governance pharmacist, a Reader in Pharmacy Practice, and a Professor of Medical Education - agreed the final analysis.

\subsection{Ethics}

The research was deemed eligible for Proportionate Review by the first available committee. It was approved by the Proportionate Review Sub-committee of the East Midlands - Nottingham 2 Research Ethics Committee (reference 15/EM/0353). 


\section{Results}

Figure 1 summarises the processing of incidents. Of 1552 extracted incidents, 85 were excluded. Reasons were: not an individual patient error (37); adverse drug reaction without error (12); error occurring in primary care but reported in secondary care (12); incident relating to equipment (7); and other reason (17). Fifty-five incidents contained errors at more than one stage of medication delivery and were duplicated. This resulted in a final dataset of 1522 medication errors, from 1467 incident reports, for analysis.

\subsection{Characteristics}

Error characteristics are summarised in Table 1. The majority (88\%) occurred during administration (822; 54\%) or prescribing $(517 ; 34 \%)$. Most reported errors led to insignificant $(1130 ; 74 \%)$ or minor $(375 ; 24 \%)$ harm; $17(1 \%)$ were classified as moderate, and none caused severe harm or death within the five year study period. In contrast, 277 (18\%) reported errors had potential to cause moderate harm, $111(7 \%)$ major harm, and 19 (1\%) catastrophic harm. Many did not cause harm because they were intercepted before reaching patients; staff reporting incidents often judged that significant harm could have occurred had they not been detected. Most were reported by nurses (682; 45\%). Pharmacists and doctors reported 163 (11\%) and 151 (9\%) respectively.

Neonates $(291 ; 19 \%)$ and infants $(230 ; 15 \%)$ were most likely to be involved in reported errors. Almost half occurred on pediatric medical wards (750; 49\%); 235 (15\%) were reported in community settings and $208(14 \%)$ in neonatal units (Table 2). Dosing errors occurred in 451 (32\%) of reported errors overall, and in over half of prescribing errors (54.1\%). Other common error types were omitted/delayed doses (288; 20\%), wrong frequency $(191 ; 14 \%)$ and wrong medicine $(174 ; 12 \%)$ (Table 3 ). Drugs most frequently reported in errors were antimicrobials $(329 ; 21 \%)$, paracetamol (135; 9\%), IV fluids (102; 7\%), and vaccines (93; 6\%) (Table 4).

\subsection{Areas of particular risk}

Table 5 identifies the high-risk patient groups, drugs, settings, and error types that represent QI targets. The highest number of reported errors occurred in neonates, 
often in NICU settings. High-risk drugs were antimicrobials, paracetamol, IV fluids and vaccines. Dosing errors were commonly reported and often associated with significant potential harm; medication omissions were also common. Table 5 also shows how the validation steps of discussing with stakeholders and reviewing published evidence helped to confirm identification of $Q$ I targets. Box 1 shows two example incidents relating to areas of risk.

\section{Discussion}

This study identified high-risk areas of practice that represent potential starting points for QI initiatives, which include neonates, NICU settings, drugs such as antimicrobials, paracetamol, IV fluids, and vaccines, and medication dosing and omissions. The validity of these targets derives from analysis of a comprehensive dataset of reported medication errors in pediatric patients in all secondary care settings, aggregated across an entire geographic region, triangulated against published evidence and the informed opinion of expert stakeholders, who are also potential improvers. Pending confirmation, we suggest that these targets may apply in other locations and that others wishing to improve pediatric medication safety may find our methodology useful.

Breaking down pediatric medication error into areas of risk enables clinicians, faced with finite time and resources, to prioritise quality improvement efforts. Moreover, certain areas of risk are associated with specific behaviours that lead to errors. Dosing errors, for example, commonly arise from miscalculations and confusion around individualised dosing.[8] Armed with information that this type of error is frequently reported, clinicians involved in QI might respond by offering specific training in dose calculations.

Use of critical incident data can go further still: after areas of risk are identified, causes of errors can be investigated by analysing free-text descriptions of what went wrong.[36,43,44] Answering the 'why' question can guide development of interventions and make them more likely to be effective. Box 2 presents a worked example of how in-depth analysis of errors in prescribing and administering IV paracetamol informed potential solutions. 
This approach addresses limitations of using incident data in research, but also goes beyond their typical use in risk management. In that context, learning from incident reporting is usually from single cases that point to critical, rectifiable safety hazards,[16] and detailed investigation of incidents leading to severe harm.[27] While necessary, analysing single cases is resource-intensive and insufficient to completely address pediatric medication errors, which are highly variable in type. It also fails to maximise learning from errors that do not lead to harm, despite evidence showing that near-misses offer important insights.[23,28] We recognise that incidents cannot be considered representative, and that numbers are affected by reporting rate and clinical activity levels. That a type of incident is reported frequently, however, is an indicator of a clinically-important problem than can be validated with other evidence. We suggest that our approach, summarised in Figure 2, of aggregating a large number of locally collected incidents and using them to identify QI targets, offers added benefits beyond traditional use of incidents.

A strength of our work is that we obtained data from an entire region, across the full spectrum of secondary care, meaning that this is among the largest studies of reported medication errors in children. We chose to include children treated in all secondary care settings (both adult and pediatric), not just those on dedicated pediatric wards, as we deemed that children looked after in non-specialist areas may have been at risk of error.

Our work also has important limitations. First, unlike studies using prospective reporting, we made use of existing incidents. [45] Reports can be incomplete or inaccurate, leading to incomplete data capture or missing parameters. We minimised this by extracting data using both patient age, and location where the incident occurred. Moreover, medication incidents are less likely to be incomplete because they are routinely vetted by MGPs after reporting. Second, we extracted incidents from all secondary care settings. This may limit direct comparison with other critical incident datasets, though it broadened our scope to identify risks. Third, not all risks can be identifying using incident data. For example, we found no reports about incomplete prescriptions or incorrect use of abbreviations, errors frequently seen in prospective studies.[3] Incident reporting should therefore be used alongside other forms of data collection, such as drug chart audit.[46] Fourth, most errors within our dataset were 
detected before reaching patients, or led to only minor harm. This affected identification of risk, which depends on error severity. Our triangulation steps, however, offset this limitation by providing information on severity of error types. Fifth, our validation steps helped to offset the limitations of critical incidents, but did not use research-level systematicity; instead, they were intended to mirror what a clinician could reasonably do in practice.

\section{Recommendations and conclusion}

Our research recommendation is for further study clarifying the specific types and underlying causes of medication errors in children. Multiple methods of study including prospective designs, critical incident studies, and qualitative approaches could help build a more complete picture than any single method alone. Research to evaluate interventions which address the improvement targets identified is also needed.

Curricula should prioritise high-risk areas of practice. For example, this might involve emphasis on calculations at undergraduate level, to prevent dosing errors, or specific induction in the use of high-risk medications such as aminoglycoside antimicrobials during postgraduate induction.

Our practice recommendation is that clinicians consider the areas of risk identified here as potential starting points for QI. We recommend, too, that clinicians consider using aggregated incident reports at local or regional level to guide their own QI priorities and provide insights into errors' underlying causes. While critical incidents are not a panacea,[16] this study suggests that they can play an important role in combatting pediatric medication error.

\section{Acknowledgements}

The authors would like to thank the Royal Belfast Hospital for Sick Children, whose Research Fellowship supported Richard Conn in conducting this work. We would also like to thank Professor Karen Mattick for comments on a draft of this article. 


\section{References}

[1] Donaldson LJ, Kelley ET, Dhingra-Kumar N, Kieny MP, Sheikh A. Medication Without Harm: WHO's Third Global Patient Safety Challenge. Lancet 2017;389(10080):1680-1681. doi:10.1016/S0140-6736(17)31047-4

[2] Kaushal R, Bates DW, Landrigan C, et al. Medication errors and adverse drug events in pediatric inpatients. JAMA. 2001;285(16):2114-2120. doi:10.1097/00132586-200206000-00041

[3] Ghaleb MA, Barber N, Franklin BD, Wong ICK, Chi I, Wong K. The incidence and nature of prescribing and medication administration errors in paediatric inpatients. Arch Dis Child 2010;95:113-118. doi:10.1136/adc.2009.158485

[4] Cass $\mathrm{H}$. Reducing paediatric medication error through quality improvement networks; where evidence meets pragmatism. Arch Dis Child 2016;101(5):26-29. doi:10.1136/archdischild-2015-309007

[5] Ghaleb MA, Barber N, Franklin BD, Yeung VWS, Khaki ZF, Wong ICK. Systematic review of medication errors in pediatric patients. Ann Pharmacother 2006;40(10):1766-1776. doi:10.1345/aph.1G717

[6] Wong ICK, Ghaleb MA, Franklin BD, Barber N. Incidence and nature of dosing errors in paediatric medications: A systematic review. Drug Saf 2004;27(9):661670. doi:10.2165/00002018-200427090-00004

[7] Rinke ML, Bundy DG, Velasquez $\mathrm{C}$ a, et al. Interventions to reduce pediatric medication errors: A systematic review. Pediatrics 2014;134:338-360. doi:10.1542/peds.2013-3531

[8] Wong ICK, Wong LYL, Cranswick NE. Minimising medication errors in children. Arch Dis Child 2009;94(2):161-164. doi:10.1136/adc.2007.116442

[9] Lesar TS. Tenfold Medication Dose Prescribing Errors. Ann Pharmacother 2002;36:1833-1839.

[10] Suresh G, Horbar JD, Plsek $P$, et al. Voluntary anonymous reporting of medical errors for neonatal intensive care. Pediatrics 2004;113(6):1609-1618. doi:10.1542/PEDS.113.6.1609

[11] Simpson JH, Lynch R, Grant J, Alroomi L. Reducing medication errors in the neonatal intensive care unit. Arch Dis Child Fetal Neonatal Ed 2004;89(6):F4802. doi:10.1136/adc.2003.044438

[12] Cote CJ, Notterman DA, Karl HW, Weinberg JA, McCloskey C. Adverse Sedation Events in Pediatrics: A Critical Incident Analysis of Contributing Factors. Pediatrics 2000;105(4):805-814. doi:10.1542/peds.105.4.805 
[13] Lesar TS. Tenfold medication dose prescribing errors. Ann Pharmacother 2002;36:1833-1839.doi:10.1345/aph.1C032

[14] Ross LM, Wallace J, Paton JY, Wallace J. Medication errors in a paediatric teaching hospital in the UK: Five years operational experience. Arch Dis Child 2000;83(6):492-497. doi:10.1136/adc.83.6.492

[15] Cousins DH, Gerrett D, Warner B. A review of medication incidents reported to the National Reporting and Learning System in England and Wales over 6 years (2005-2010). Br J Clin Pharmacol 2012;74:597-604. doi:10.1111/j.13652125.2011.04166.x

[16] Pham JC, Girard T, Pronovost PJ. What to do with healthcare Incident Reporting Systems. J Public health Res 2013;2(3):27. doi:10.4081/jphr.2013.e27

[17] Kozer E, Scolnik D, Jarvis AD, Koren G. The effect of detection approaches on the reported incidence of tenfold errors. Drug Saf 2006;29(2):169-174. doi:10.2165/00002018-200629020-00007

[18] Sari AB, Sheldon TA, Cracknell A, Turnbull A. Sensitivity of routine system for reporting patient safety incidents in an NHS hospital: retrospective patient case note review. BMJ 2007;334:79.doi:10.1136/bmj.39031.507153.AE

[19] Macrae C. The problem with incident reporting. BMJ Qual Saf 2016;25(2):71- 75. doi:10.1136/bmjqs-2015-004732

[20] Noble DJ, Pronovost PJ. Underreporting of patient safety incidents reduces health care's ability to quantify and accurately measure harm reduction. J Patient Saf 2010;6:247-250.doi:10.1097/PTS.0b013e3181fd1697

[21] Royal College of Physicians. Supporting junior doctors in safe prescribing. London: RCP, 2017. https://www.rcplondon.ac.uk/projects/outputs/supportingjunior-doctors- safe-prescribing (Accessed 25 Mar 2020)

[22] World Health Organization. Conceptual Framework for the International Classification of Patient Safety. Geneva: WHO, 2009. https://www.who.int/patientsafety/taxonomy/icps_full_report.pdf (Accessed 25 Mar 2020)

[23] Battles JB, Lilford RJ. Organizing patient safety research to identify risks and hazards. BMJ Qual Saf 2003;12 Suppl 2:ii2-ii7. doi:10.1136/qhc.12.suppl_2.ii2

[24] Department of Health. An organisation with a memory - Report of an expert group on learning from adverse events in the NHS. London: TSO, 2000.

https://webarchive.nationalarchives.gov.uk/20130105144251/http://www.dh.gov.u k/prod_consum_dh/groups/dh_digitalassets/@dh/@en/documents/digitalasset/dh _4065086.pdf (Accessed 25 Mar 2020) 
[25] Walsh K. When I say.. triangulation. Med Educ 2013;47(9):866-866. doi:10.1111/medu.12241

[26] National Patient Safety Agency. Review of patient safety for children and young people. London: NPSA, 2009.

[27] Subhedar N V, Parry HA. Critical incident reporting in neonatal practice. Arch Dis Child Fetal Neonatal Ed 2010;95(5):F378-82. doi:10.1136/adc.2008.137869

[28] Shaw KN, Lillis KA, Ruddy RM, et al. Reported medication events in a paediatric emergency research network: Sharing to improve patient safety. Emerg Med $J$ 2013;30(10):815-819. doi:10.1136/emermed-2012-201642

[29] Medicines and Healthcare products Regulatory Agency. Intravenous paracetamol (Perfalgan): risk of accidental overdose, especially in infants and neonates. Drug Saf Updat 2010;3:2-3.

[30] National Patient Safety Agency. Overdose of intravenous paracetamol in infants and children | Signal 1293F. London: NPSA, 2010.http://webarchive.nationalarchives.gov.uk/20171030130125/http://www.nrls. npsa.nhs.uk/resources/clinical-specialty/paediatrics-and-childhealth/?entryid45=83757 (Accessed 25 Mar 2020)

[31] National Patient Safety Agency. Safer use of intravenous gentamicin for neonates. London: NPSA, 2010.https://www.sps.nhs.uk/wpcontent/uploads/2018/02/2010-NRLS-1085-Safer-use-of-inonates-2010.02.03v1.pdf (Accessed 25 Mar 2020)

[32] Armon K, Riordan A, Playfor S, Millman G, Khader A. Hyponatraemia and hypokalaemia during intravenous fluid administration. Arch Dis Child 2008;93(4):285-287. doi:10.1136/adc.2006.093823

[33] Hyponatraemia Inquiry Team. The Inquiry into Hyponatraemia-Related Deaths Report. 2018. http://www.ihrdni.org/Full-Report.pdf (Accessed 25 Mar 2020)

[34] Feikema SM, Klevens RM, Washington ML, Barker L. Extraimmunization among US children. J Am Med Assoc 2000;283(10):1311-1317. doi:10.1001/jama.283.10.1311

[35] World Health Organization. Global Manual on surveillance of Adverse Events Following Immunization. 2014. http://www.who.int/vaccine_safety/publications/Global_Manual_revised_12 102015.pdf?ua=1 (Accessed 25 Mar 2020)

[36] Rees P, Edwards A, Powell C, et al. Pediatric immunization-related safety incidents in primary care: A mixed methods analysis of a national database. Vaccine 2015;33(32):3873-3880. doi:10.1016/j.vaccine.2015.06.068 
[37] Kaushal R, Goldmann DA, Keohane CA, et al. Medication errors in paediatric outpatients. Qual Saf Health Care 2010;19(6):e30.

doi:10.1136/qshc.2008.031179

[38] Sutcliffe K, Stokes G, O'Mara-Eves A, et al. Paediatric medication error: a systematic review of the extent and nature of the problem in the UK and international interventions to address it. London: EPPI-Centre, 2014. https://eppi.ioe.ac.uk/cms/Portals/0/PDF\%20reviews\%20and\%20summarie s/Paediatric\%20medication\%20error\%202014\%20Sutcliffe\%20report.pdf?ve $r=2014-11-20-161504-377$ (Accessed 25 Mar 2020)

[39] Huynh C, Wong ICK, Correa-West J, et al. Paediatric patient safety and the need for aviation black box thinking to learn from and prevent medication errors. Pediatr Drugs 2017;19:99-105.doi:10.1007/s40272-017-0214-8

[40] Koren G, Barzilay Z, Greenwald M. Tenfold errors in administration of drug doses: a neglected iatrogenic disease in pediatrics. Pediatrics 1986;77:848-849.

[41] Keers RN, Williams SD, Cooke J, Ashcroft DM. Prevalence and nature of medication administration errors in health care settings: A systematic review of direct observational evidence. Ann Pharmacother 2013;47(2):237-256. doi:10.1345/aph.1R147

[42] Poder TG, Maltais S. Systemic analysis of medication administration omission errors in a tertiary-care hospital in Quebec. Health Information Management Journal 2018; ePub Jun 18. doi:10.1177/1833358318781099

[43] Williams $\mathrm{H}$, Edwards $\mathrm{A}$, Hibbert $\mathrm{P}$, et al. Harms from discharge to primary care: mixed methods analysis of incident reports. Br J Gen Pract 2015;65(641):e829e837. doi:10.3399/bjgp15X687877

[44] Rees P, Edwards A, Powell C, et al. Patient Safety Incidents Involving Sick Children in Primary Care in England and Wales: A Mixed Methods Analysis. PLOS Med 2017;14:e1002217.doi:10.1371/journal.pmed.1002217

[45] Snijders C, van Lingen RA, Klip H, et al. Specialty-based, voluntary incident reporting in neonatal intensive care: description of 4846 incident reports. Arch Dis Child Fetal Neonatal Ed 2009;94(3):F210-5. doi:10.1136/adc.2007.135020

[46] Olsen S, Neale G, Schwab K, et al. Hospital staff should use more than one method to detect adverse events and potential adverse events: Incident reporting, pharmacist surveillance and local real-time record review may all have a place. Qual Saf Heal Care 2007;16(1):40-44. doi:10.1136/qshc.2005.017616 
Table 1. Summary characteristics of reported medication errors occurring in pediatric patients in Northern Ireland secondary care, 2011-2015 $(n=1522)$

\begin{tabular}{lll}
\hline Characteristic & $\begin{array}{l}\text { Number of } \\
\text { incidents }(n)\end{array}$ & Percentage
\end{tabular}

\section{Stage of medication delivery}

\begin{tabular}{lll}
\hline Prescribing & 517 & 34.0 \\
\hline Administration & 822 & 54.0 \\
\hline Preparation/Dispensing & 143 & 9.4 \\
\hline Monitoring & 37 & 2.4 \\
\hline Other & 3 & 0.002
\end{tabular}

\section{Reported degree of harm sustained}

\begin{tabular}{lll}
\hline Insignificant & 1130 & 74.2 \\
\hline Minor & 375 & 24.6 \\
Moderate & 17 & 1.1 \\
\hline Severe & 0 & 0 \\
Catastrophic & 0 & 0
\end{tabular}

\section{Reported degree of potential harm}

\begin{tabular}{lcc}
\hline Insignificant & 229 & 15.0 \\
\hline Minor & 886 & 58.2 \\
Moderate & 277 & 18.2 \\
\hline Major & 111 & 7.3 \\
\hline Catastrophic & 19 & 1.2
\end{tabular}

\section{Age of patient involved}

\begin{tabular}{lll}
0 - 27 days & 291 & 19.1 \\
\hline 28 days -12 months & 230 & 15.1
\end{tabular}




\begin{tabular}{lcc}
\hline 13 months - 2 years & 75 & 4.9 \\
\hline 2 - 5 years & 220 & 14.5 \\
\hline 6 - 11 years & 219 & 14.4 \\
\hline 12 -16 years & 324 & 21.3 \\
\hline Not specified & 163 & 10.7 \\
\hline Job role of staff member reporting incident & \\
\hline Nursing & 682 & 44.8 \\
\hline Pharmacy & 163 & 10.7 \\
\hline Medical & 151 & 9.9 \\
\hline Managerial & 42 & 2.8 \\
\hline Other & 27 & 1.8 \\
\hline Unknown & 457 & 30.0 \\
\hline
\end{tabular}


Table 2. Reported medication errors by area of practice $(n=1522)$

\begin{tabular}{lll}
\hline Practice area & Number of incidents $(\boldsymbol{n})$ & Percentage (\%) \\
\hline Pediatric ward (medical) & 750 & 49.3 \\
\hline Community pediatrics & 235 & 15.4 \\
\hline Neonatal unit & 208 & 13.7 \\
\hline Postnatal ward/delivery suite & 87 & 5.7 \\
\hline Pediatric ward (surgical) & 61 & 2.6 \\
\hline Emergency department & 51 & 3.4 \\
\hline Adult ward (medical) & 37 & 2.4 \\
\hline Adult ward (surgical) & 29 & 1.9 \\
\hline Outpatients & 9 & 0.6 \\
\hline Ambulatory unit & 3 & 0.2 \\
\hline Adult ward (other) ${ }^{*}$ & 2 & 0.1 \\
\hline Not specified/other & 50 & 3.3 \\
\hline${ }^{*}$ Incidents in these settings was likely to involve older children, aged 14-15 years
\end{tabular}


Table 3. Reported medication errors by type, overall and within prescribing and administration

\begin{tabular}{llll}
\hline Error type & $\begin{array}{l}\text { Overall } \\
(\boldsymbol{n} ; \%)\end{array}$ & $\begin{array}{l}\text { Prescribing } \\
(\boldsymbol{n} ; \%)\end{array}$ & $\begin{array}{l}\text { Administration } \\
(\boldsymbol{n} ; \%)\end{array}$ \\
\hline $\begin{array}{l}\text { Dose or strength was wrong or } \\
\text { unclear }\end{array}$ & $451(29.6)$ & $280(54.1)$ & $148(18.0)$ \\
\hline Omitted/delayed medicine or dose & $288(18.9)$ & $44(8.5)$ & $205(24.9)$ \\
\hline Wrong/unclear frequency & $191(12.5)$ & $60(11.6)$ & $131(15.9)$ \\
\hline $\begin{array}{l}\text { Wrong/unclear drug/medicine } \\
\text { Wrong method of preparation }\end{array}$ & $174(11.4)$ & $34(6.6)$ & $130(15.8)$ \\
\hline $\begin{array}{l}\text { Mismatch between patient and } \\
\text { medicine }\end{array}$ & $37(2.4)$ & $11(2.1)$ & $22(2.7)$ \\
\hline Delay or failure to monitor & $37(2.4)$ & $0(0)$ & $0(0)$ \\
\hline Expiry date wrong & $35(2.3)$ & $0(0)$ & $18(2.2)$ \\
\hline $\begin{array}{l}\text { Wrong/transposed/omitted medicine } \\
\text { label }\end{array}$ & $30(2.0)$ & $0(0)$ & $0(0)$ \\
\hline Medication incorrectly stored & $23(1.5)$ & $0(0)$ & $21(2.5)$ \\
\hline Other medication error & $213(14.0)$ & $86(16.6)$ & $113(13.7)$ \\
\hline Total & 1522 & 517 & 822 \\
\hline
\end{tabular}


Table 4. Medicine/drug class involved in errors, overall and within prescribing and administration

\begin{tabular}{|c|c|c|c|}
\hline Medication & Overall (n; \%) & Prescribing $(n ; \%)$ & Administration ( $n ; \%)$ \\
\hline Antimicrobials & $329(20.8)$ & $118(21.8)$ & $173(20.4)$ \\
\hline Paracetamol & $135(8.5)$ & $65(12.0)$ & $60(7.1)$ \\
\hline IV fluids & $102(6.4)$ & $41(7.6)$ & $50(5.9)$ \\
\hline Vaccines & $93(5.9)$ & $0(0)$ & $90(16.6)$ \\
\hline Opiates & $73(4.6)$ & $23(4.3)$ & $38(7.0)$ \\
\hline TPN & $64(4.1)$ & $41(7.6)$ & $19(3.5)$ \\
\hline Benzodiazepines & $59(3.7)$ & 18(3.3) & $31(5.7)$ \\
\hline Steroids & $46(2.9)$ & $22(4.1)$ & $22(4.1)$ \\
\hline Anticonvulsants & $46(2.9)$ & $17(3.1)$ & $22(4.1)$ \\
\hline NSAIDs & $43(2.7)$ & $22(4.1)$ & $19(3.5)$ \\
\hline Antacids & $32(2.0)$ & $12(2.2)$ & $16(3.0)$ \\
\hline Anticoagulants & $26(1.6)$ & $9(1.7)$ & $16(3.0)$ \\
\hline Insulin & $26(1.6)$ & $12(2.2)$ & $14(2.6)$ \\
\hline Other & $351(22.2)$ & $101(18.7)$ & $230(27.1)$ \\
\hline Unknown & $140(8.9)$ & $40(7.4)$ & $47(5.5)$ \\
\hline Total & $1580^{*}$ & $541^{*}$ & $847^{*}$ \\
\hline
\end{tabular}

${ }^{*}$ Totals exceed total number of errors, as an error could involve more than one drug 
Table 5. Published evidence and stakeholder advice supporting validity of identified risks

\section{Area of risk Evidence of frequency and/or severity of medication errors within area of risk}

\section{Patients and settings}

Neonates (0- Incidents are commonly reported in neonates and NICU 28 days), settings[14,26]

NICU setting

Studies using prospective data collection methods show that neonates and infants are at greatest risk of medication error[2]

Neonates are vulnerable to harm from error due to immaturity and a prolonged need for intensive care support[27]

A medication safety committee - part of the statuatory body responsible for arranging and commissioning public health care in Northern Ireland (the Medication Safety-Subgroup of the NI Health and Social Care Board) - requested that the NICU setting be specifically considered

\section{Drugs}

Paracetamol Very commonly used drug in pediatrics, previously $(P, A) \quad$ associated with errors[2,28]

Reported incidents in literature around IV paracetamol[29,30]

An existing QI programme within the regional children's hospital is following adverse incidents with IV paracetamol

Antimicrobials Previous incident studies show antimicrobials commonly $(P, A) \quad$ involved in errors[14,28]

Most commonly involved class in a large systematic review[5]

Specific problems with aminoglycosides, associated with high risk of harm[31]

IV fluids $(\mathrm{P}, \mathrm{A}) \quad$ Commonly involved in errors in other studies[2,14,28] Inappropriate use/errors associated with harm, in the context 
of hyponatraemia[32]

Deemed important by all stakeholder advisory groups in view of recently published report of the Inquiry into Hyponatraemia-related Deaths, associated with the use of IV fluids in Northern Ireland[33]

Vaccines (A) Commonly involved in errors;[34] recognised by WHO as a priority for improvement[35]

Non-emergency drugs given in specific, controlled circumstances; opportunities exist to improve process to prevent errors[36]

\section{Error types}

Dosing errors Dosing errors have been shown to be common, in studies $(P, A) \quad$ using incident reporting[26,28] and other forms of data collection,[3,5,6,37,38]

Occurrence relates to specific behavioural causes that should be addressed within solutions - increased need for individualised dosing and calculations etc.[39]

Associated with significant risk of harm, especially specific types like tenfold dosing errors $[5,40]$

Omissions Consistently amongst the commonest three subtypes of

(A) medication administration error[41]

Harm difficult to quantify, but an important, potentially remediable problem[42] 


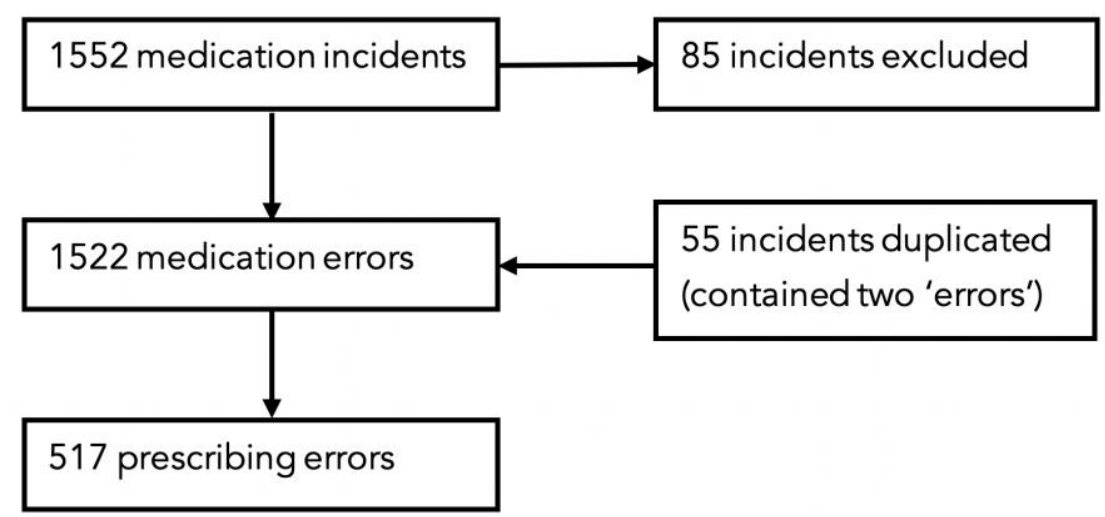

822 administration errors

143 dispensing errors

37 monitoring errors

3 other errors

Figure 1. Flow diagram showing processing of reported incidents 


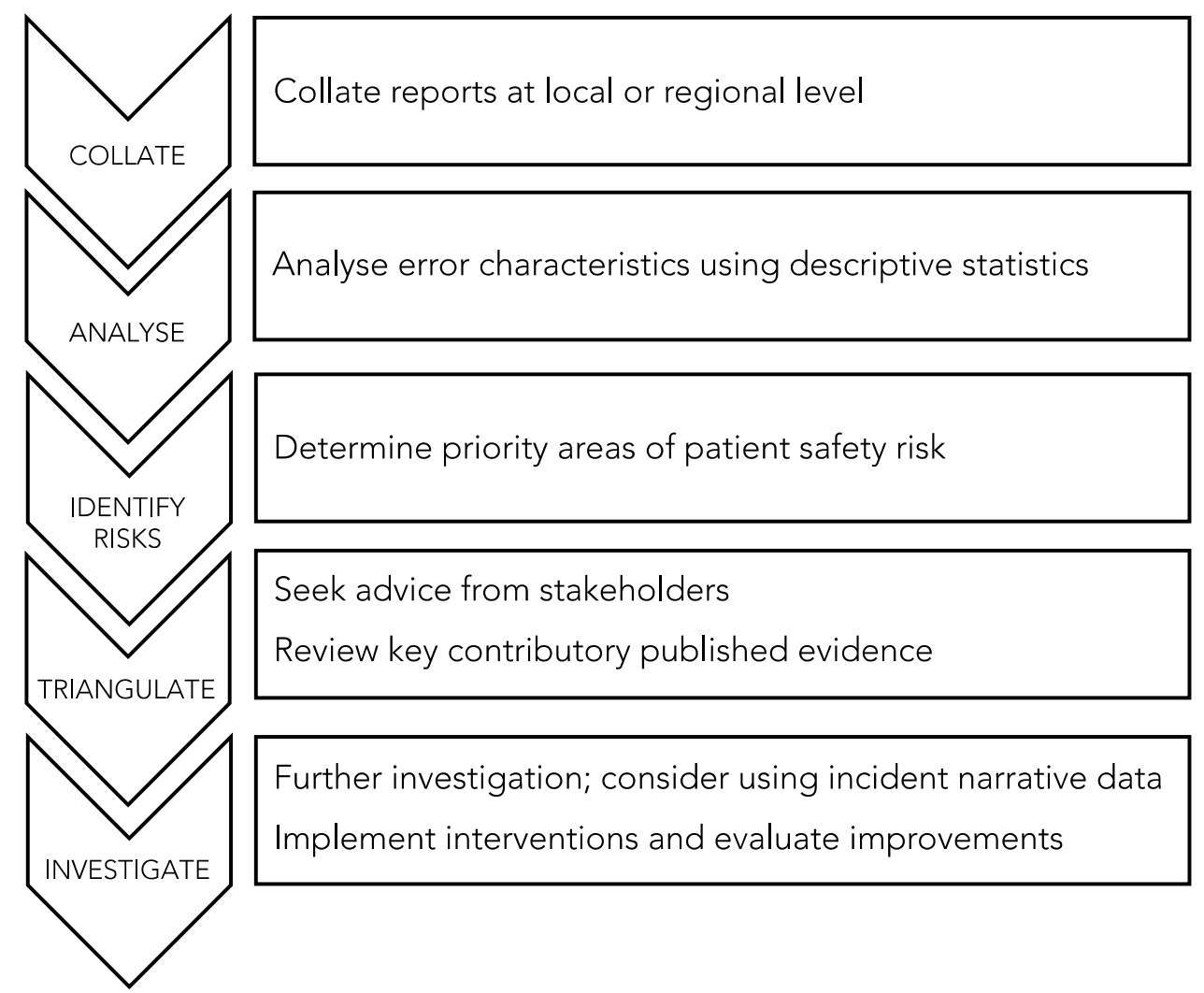

Figure 2. Suggested steps in identifying patient safety risks from reported medication errors. 
Box 1. Example incidents

Dosing error in prescribing paracetamol. Minor harm; potential harm - catastrophic

A two day old term neonate was taken to theatre for a laparotomy for possible bowel atresia. Intraoperatively the baby was given a tenfold overdose of paracetamol by the anaesthetic registrar. Baby was immediately commenced on $\mathrm{N}$-acetyl cysteine, and admitted to the ward post-operatively.

Administration error with antimicrobials. Moderate harm.

Ward was very busy. Patient was due to commence intravenous (IV) antibiotics. First dose of IV tazocin [piperacillin/tazobactam] and vancomycin were drawn up and administered as a bolus over five minutes. The patient complained of sore ears and a 'stingy' sensation following administration of vancomycin. His face became flushed and his blood pressure dropped. The doctor was informed urgently. Vancomycin should have been administered as infusion over one hour. An IV fluid bolus was given. Blood pressure improved and the ear pain and facial redness settled. 
Box 2. Case study: using incident data to further investigate identified areas of risk We identified intravenous (IV) paracetamol prescribing and administration as a high-risk area. Local incidents had also led to a quality improvement (QI) project being initiated in the regional children's hospital. To further investigate this, and contribute to existing QI work, we extracted data specifically relating to paracetamol prescribing and administration errors.

We identified 47 errors involving IV paracetamol: 23 in prescribing and 24 during administration. Only insignificant or minor harm was reported, but over $30 \%$ had the potential to cause moderate, severe or catastrophic harm. We then analysed error descriptions.

Seventeen prescribing errors related to incorrect dosing. Seven of these occurred because doctors were unaware of, or did not apply, the $30 \mathrm{mg} / \mathrm{kg} / \mathrm{day}$ dose threshold applicable to infants under $10 \mathrm{~kg}$ in weight. Six errors occurred when practitioners adopted the practice of inappropriately prescribing paracetamol 'as required' by more than one route - for example, IV/PO - even though the correct dose for each route may be different.

Twelve administration errors occurred when patients moved between clinical areas. A typical example was a child receiving a second dose of paracetamol in the operating theatre because it wasn't noted that they had already received paracetamol on the ward. Analysis suggested that multiple sources of written information, and medications not being covered during staff handover, contributed to these errors.

Findings had clear implications for quality improvement - suggesting, for example, that education around specific aspects of IV paracetamol dosing, and streamlining documentation for pediatric patients transferring to theatre could be beneficial and were provided to the QI team working on the issue. 